\title{
Divulgação da ciência na universidade pública: análise de conteúdo de informativo produzido por uma assessoria de comunicação
}

\author{
Raul Ramalho \\ Universidade Estadual da Paraíba, Departamento de Comunicação Social, Campina Grande, PB, Brasil \\ ORCID: https://orcid.org/0000-0002-8814-4791
}

\section{Anabela Gradim}

Universidade da Beira Interior, Departamento de Comunicação, Filosofia e Política, Covilhã, Portugal ORCID: https://orcid.org/0000-0001-6968-1957

\section{Resumo}

Este artigo tem o objetivo de contribuir com as discussões sobre o trabalho da assessoria de imprensa / comunicação na divulgação de pesquisas científicas realizadas em universidades públicas. Para isto, analisa os conteúdos do boletim informativo @UFRNotícias, produzido pela Agência de Comunicação da Universidade Federal do Rio Grande do Norte, no Brasil, relativos a investigações científicas feitas na citada organização e a temáticas administrativas (eventos, serviços e divulgação institucional). O debate teórico envolve conceitos de assessoria de comunicação e de imprensa, comunicação pública associada à divulgação científica e a importância da comunicação organizacional e estratégica na consolidação da imagem e na legitimação social de uma instituição pública de ensino e pesquisa. Como metodologia, a análise de conteúdo foi utilizada para formular categorias temáticas relacionadas à divulgação científica, observar o formato do produto midiático e fazer inferências sobre as condições de produção do material e sobre o contexto social e institucional no qual ele está inserido. A amostra é composta por 24 boletins (144 textos) enviados em agosto de 2018. Os resultados mostram que os conteúdos relacionados às pesquisas científicas têm pouco destaque (ausência de fotografias e vídeos) e espaço no boletim (cerca de $8 \%$ do total), e são, na sua maioria, superficiais. O formato padronizado e a cobertura heterogênea demonstram uma tentativa de divulgar conteúdos que atendam interesses de públicos diferentes como jornalistas e comunidade acadêmica. 


\section{Palavras-chave}

Divulgação científica; Assessoria de comunicação e de imprensa;

Comunicação pública; Universidade pública; @UFRNotícias

\section{Introdução}

A popularização das Tecnologias da Informação e Comunicação (TICs), contextualizadas dentro do fenômeno da midiatização (HEPP; HASEBRINK, 2018), impactam diretamente o modo de as instituições tentarem legitimar-se socialmente. As universidades não se encontram fora desta realidade. Com uma diversidade de canais abertos para se comunicar com os públicos internos e externos, as instituições públicas de ensino superior reorganizam suas assessorias de comunicação para dar conta de atender tamanha demanda e uniformizar os conteúdos.

Levando em consideração o contexto brasileiro em que há uma pressão para a divulgação de pesquisas científicas, o que muitos apontam como "produtivismo" (OURIQUES, 2011; REGO, 2014), uma questão vem à tona: como é que as informações sobre investigações científicas são tratadas e divulgadas pelas assessorias de comunicação em meio a uma torrente de outros conteúdos que disputam a atenção desse setor administrativo universitário?

Para indicar respostas, este artigo tem o objetivo de analisar o conteúdo do boletim informativo intitulado @UFRNotícias, produzido pela Agência de Comunicação da Universidade Federal do Rio Grande do Norte (UFRN), no Brasil, e enviado por e-mail, de uma a três vezes por dia, exceto no sábado e no domingo, para a comunidade acadêmica e para a imprensa local e nacional. Além disso, o material divulgado é colocado no site institucional da universidade.

No caminho do que já fizeram, por exemplo, Teixeira (2016), Campos (2018), Passos Filho (2018) e Costa e Lopes (2020), os quais apontam avanços, sem deixar de indicar limitações e lacunas na atividade de comunicar ciência por parte de instituições públicas de pesquisa e ensino no Brasil, a opção por analisar o citado produto midiático (@UFRNotícias) é uma tentativa de contribuir criticamente, para a compreensão de como se dá a relação entre assessoria de comunicação e pesquisa científica no contexto descrito, considerando, a partir dos conceitos de comunicação organizacional / institucional e comunicação pública, 
os possíveis entraves para a divulgação da ciência por parte das universidades públicas brasileiras, já tão afetadas pela falta de financiamento.

Partimos da hipótese de que o @UFRNotícias dá divulgação a assuntos científicos, mas tem um forte caráter institucional (ao divulgar atos administrativos, por exemplo), o que mostra a função heterogênea de cobertura de uma assessoria de comunicação dentro de uma universidade pública (AGUIAR, 2012). Além disso, o elevado número de publicações do boletim pode demonstrar: (a) a efervescência da vida acadêmica da UFRN; (b) o atendimento à lógica do imediatismo e da novidade exigida pelos meios jornalísticos (HERBELÊ, 2012).

Para realizar este estudo, utilizamos a Análise de Conteúdo (BARDIN, 1977; HERSCOVITZ, 2010) numa perspectiva quali-quantitativa. Visão esta que nos pede uma problematização teórica sobre a temática levantada, em especial a atuação das assessorias de comunicação, levando em conta os contextos da comunicação institucional e pública e a divulgação das ciências por parte das universidades.

\section{Papel da assessoria de imprensa e de comunicação na divulgação científica por parte das universidades}

A Agência de Comunicação da UFRN (Agecom) é o setor responsável por realizar a divulgação de assuntos relativos à universidade junto aos públicos internos e externos, utilizando estratégias variadas. 0 @UFRNotícias (visualizado de forma exemplificativa na figura 1) é enviado por e-mail em formato de boletim informativo ou newsletter para jornalistas e comunidade acadêmica cadastrados no sistema da universidade.

Os textos das notícias inseridas no boletim podem ser identificados como releases, que, apesar da popularização das relações entre instituições (fontes), jornalistas e público no geral via mídias sociais (BUENO, 2015), segundo Duarte (2016), constituem a forma mais tradicional de uma assessoria de imprensa mediar as informações a respeito de uma organização pública ou privada junto aos meios jornalísticos e podem ser definidos como:

Um material informativo com formato jornalístico produzido especificamente para servir de pauta ou informação à imprensa. [...] Utiliza técnicas jornalísticas na forma com que é redigido para apresentar um assunto de interesse que supõe público, mas como ponto de vista da organização ou fonte. (DUARTE, 2016, p. 268-269). 
Figura 1 - @UFRNotícias recebido no e-mail de um dos autores

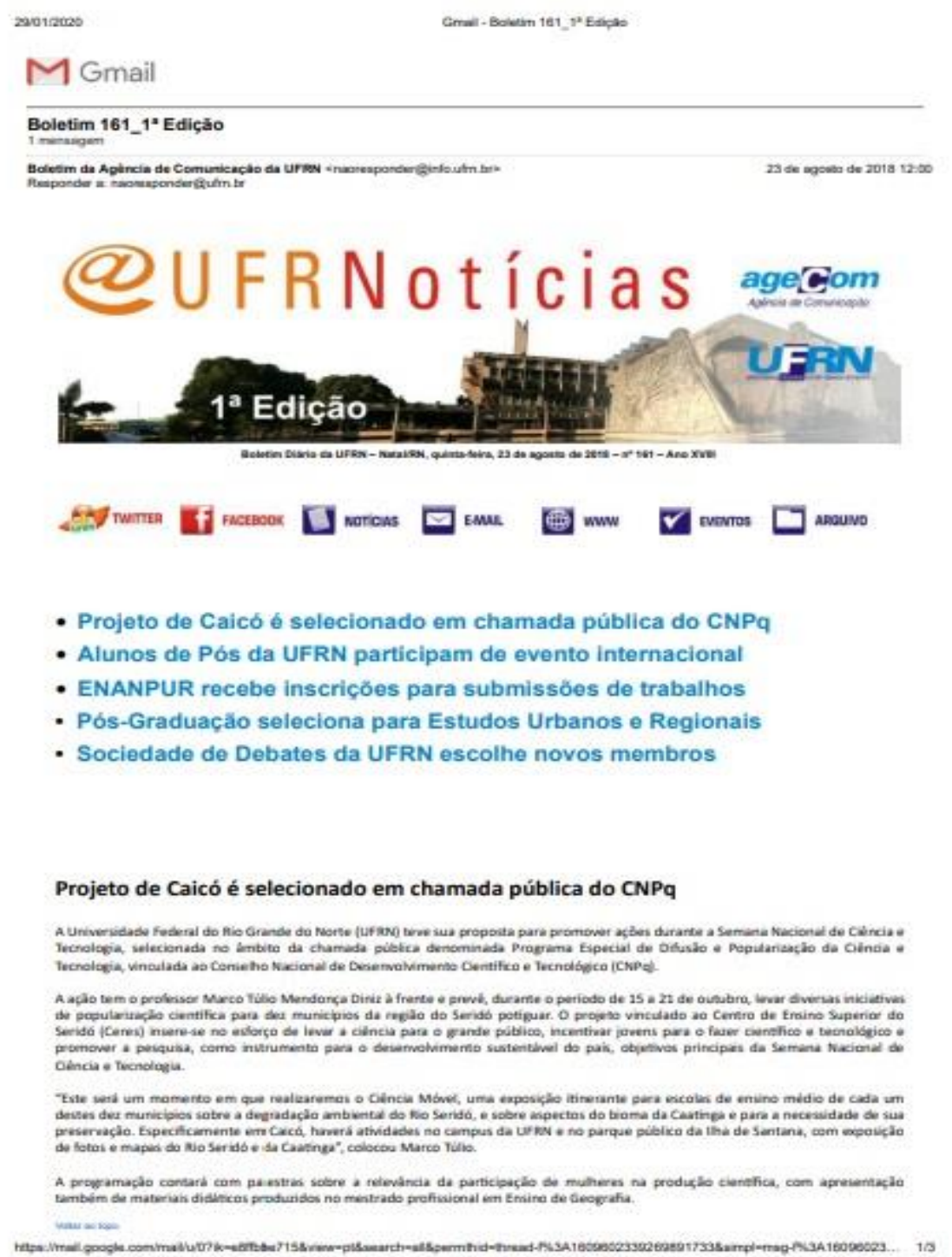

Fonte: Boletim diário da UFRN (AGÊNCIA DE COMUNICAÇÃO DA UFRN, 2018).

Embora o @UFRNotícias tenha uma linguagem jornalística (com textos em formato de notícias e reportagens especiais), justamente pelo fato de ele não ser somente direcionado aos jornalistas, entendemos que ele está integrado em uma ação, dentre tantas outras possíveis, de assessoria de comunicação (DUARTE, 2016), que no contexto brasileiro:

Presta um serviço especializado, coordenando as atividades de comunicação de um assessorado com seus públicos e estabelecendo políticas e estratégias que englobam iniciativas nas áreas de jornalismo (assessoria de imprensa), relações públicas e publicidade e propaganda. (KOPPLIN; FERRARETO, 2009, p. 11-12). 
Esses serviços integram um conjunto de atividades identificado como comunicação institucional / organizacional (BUENO, 2009). Essa atividade estratégica busca formar uma imagem positiva da instituição baseando-se na relação com públicos externos (neste caso, os jornalistas e as pessoas que têm contato com as mensagens por meio das matérias produzidas nos meios jornalísticos ou no próprio site da UFRN) e internos (a comunidade acadêmica - alunos, professores, técnicos etc.) (CURVELLO, 2016; TEIXEIRA, 2016). A perspectiva da comunicação institucional parte do princípio de que

[...] a imagem pública das organizações passa a representar um fator estratégico tão importante quanto os produtos e serviços. A comunicação ocorre, não mais por meio de algo que se diz a um público passivo, mas pela qualidade das relações estabelecidas com esses atores e pela credibilidade gerada por uma rede de relações articuladas pela empresa com seus distintos públicos. (TEIXEIRA, 2016, p. 25).

Neste sentido, o setor de assessoria de comunicação em uma instituição pública de ensino superior é fundamental, pois as universidades públicas são responsáveis por cerca de 95\% da produção científica no Brasil (ALMEIDA, 2021). Outro dado relevante é que somente 17 universidades privadas estão entre as 100 instituições públicas de ensino superior brasileiras que mais publicaram artigos científicos no quinquênio 2014-2018, sendo que as 20 primeiras são todas públicas (MOURA, 2019). Torna-se necessário, portanto, construir pontes comunicativas entre o que é produzido nas instituições, os meios jornalísticos e o público em geral. Essa função não é meramente informativa. Tal atividade, além de constituir importante fator de legitimação e fortalecimento da imagem da universidade (HERBELÊ, 2012) também contribui para a popularização da ciência, aspecto que deve ser prioridade em um país em desenvolvimento como Brasil (IVANISSEVICH, 2012), num contexto de comunicação pública (TEIXEIRA, 2016) relacionada diretamente com a comunicação científica ${ }^{1}$ (BRANDÃO, 2006). Essa associação é explicada pelo reconhecimento de que

[...] a produção e difusão do conhecimento científico incorporaram preocupações sociais, políticas econômicas e corporativas que ultrapassam os limites da ciência pura e que obrigaram as instituições de pesquisa a estender a divulgação científica além do círculo de seus pares. Entre os

\footnotetext{
${ }^{1}$ Brandão (2006) identifica o termo comunicação pública associado a pelo menos mais quatro tipos de estratégias de comunicação, além da científica. São elas: organizacional, do Estado e/ou governamental, política, da sociedade civil organizada. Neste artigo nos detivemos à relação com a comunicação científica.
} 
novos horizontes, a preocupação com o papel social da ciência na sociedade; o aumento da competitividade entre equipes e instituições de pesquisa em âmbito nacional e internacional; os altíssimos investimentos em dinheiro, tempo e capacitação dos pesquisadores; a premissa que o acesso às informações de ciência e tecnologia é fundamental para o exercício pleno da cidadania; a necessidade de posicionar a ciência e os cientistas de modo a influenciar as decisões políticas e econômicas e se legitimar perante a sociedade, o que significa despertar o interesse da opinião pública, dos políticos, da sociedade organizada e, principalmente, da mídia. (BRANDÃo, 2006, p. 4).

Para o contexto deste estudo, portanto, numa concordância com as visões de Duarte (2007) e Teixeira (2016), a comunicação pública deve contribuir para a emancipação de um povo em determinado contexto social com base na democratização da informação. Não se trata apenas de informar, mas de informar para promover cidadania, com base numa perspectiva dialógica da comunicação, buscando gerar debates construtivos em torno dos assuntos divulgados e, principalmente, dando oportunidade para que os diversos públicos envolvidos com a instituição (neste caso, uma universidade pública) sejam considerados nas discussões. Apontando a reponsabilidade social das instituições públicas de pesquisa, Cortassa, Andrés e Wursten (20172 apud CAMPOS, 2018, p. 5) apontam três razões ético / sociais para que as instituições públicas de ensino e pesquisa invistam em processos organizados de comunicação da ciência:

[...] em primeiro lugar, estão os fatores éticos e/ou morais ligados ao uso de fundos públicos; em segundo, a manutenção da credibilidade da ciência e da tecnologia a fim de que alcancem visibilidade e tenham reconhecido seu valor social (do que depende a continuidade de financiamento); e, em terceiro, a sua função de agente de democratização de acesso ao conhecimento e promoção de vocações científicas.

Necessário, portanto, que as universidades públicas formulem caminhos eficientes de divulgação científica, para proporcionarem o retorno social que lhes é esperado já que a maior parte do investimento nas pesquisas nessas instituições é oriunda dos impostos pagos pelos cidadãos.

\footnotetext{
${ }^{2}$ CORTASSA, Carina; ANDRÉS, Gonzalo; WURSTEN, Andrés. Prólogo. In: CORTASSA, Carina; ANDRÉS, Gonzalo; WURSTEN, Andrés. Comunicar la ciencia: escenarios y prácticas: memórias del V Congreso Internacional de Comunicación Pública de la Ciencias y la Tecnología. Paraná: Universidad Nacional de Entre Ríos, 2017. Apud Campos (2018).
} 


\title{
3 Metodologia
}

De caráter descritivo (OLIVEIRA, 2007), esta pesquisa trata de um objeto em específico, o @UFRNotícias. Desta forma, esta investigação constitui um estudo de caso que, de acordo com Chizzotti (2006, p. 136), “[...] visa explorar [...] um caso singular, situado na vida real contemporânea, bem delimitado e contextualizado em tempo e lugar para realizar uma busca circunstanciada de informações [...]”. É importante ressaltar que o estudo de caso deve ser feito considerando o contexto que envolve o objeto de observação (YIN, 2001). Essa associação (objeto / contexto) é importante para realizar as inferências por meio da análise de conteúdo, método utilizado aqui para avaliar o material coletado. Bardin (1977, p. 42) define a análise de conteúdo da seguinte maneira:

\begin{abstract}
Um conjunto de técnicas de análise das comunicações visando obter, por procedimentos sistemáticos e objectivos de descrição do conteúdo das mensagens, indicadores (quantitativos ou não) que permitam a inferência de conhecimentos relativos às condições de produção/recepção (variáveis inferidas) destas mensagens.
\end{abstract}

A amostra não probabilística criterial (COUTINHO, 2015) foi condensada de 13 a 24 de agosto de 2018, levando em consideração o critério de que o segundo semestre letivo do citado ano estivesse em funcionamento na graduação e pós-graduação. Nesse lapso temporal, a UFRN enviou 24 boletins (recebidos por e-mail por um dos autores), totalizando 144 textos (unidades de análise) que foram categorizados tematicamente (BARDIN, 1977; HERSCOVITZ, 2010). Neste caminho, primeiramente, compartimentamos o conteúdo em quatro categorias: (a) pesquisa científica: informações sobre investigações realizadas na UFRN, pesquisas desenvolvidas fora da UFRN, mas debatidas na universidade em eventos, simpósios etc., investigações feitas por professores e alunos da universidade e aprovadas em eventos no geral; (b) eventos: encontros, seminários, conferências realizados na UFRN ou fora dela, que não continham claramente um tema de pesquisa(s) a ser(erem) debatido(s); (c) serviços, divulgação de serviços diversos (inscrições de concursos, ações sociais, por exemplo) para a comunidade acadêmica e para o público em geral; d) divulgação institucional: atividades da reitoria e questões administrativas.

Como nosso objetivo é abordar diretamente o conteúdo que diz respeito a pesquisas científicas, dividimos essa categoria em outras cinco subcategorias temáticas: (1) área científica, conforme classificação da ciência exposta por Fachin (2005); (2) abrangência 
geográfica (local, regional, nacional ou internacional); (3) extensão textual (BARDIN, 1977): curta, média (pode ser vista na figura 1), grande e se contém imagens. Esta categorização leva em conta os formatos com os quais são enviadas as informações no boletim: a curta diz respeito a um formato intitulado "Curtas", no qual há apenas um parágrafo com informações; a média é relacionada à maneira mais usual em que os textos são enviados, divididos em parágrafos (três a sete) e a grande trata do tipo "Boletim Especial" quando a informação é enviada em destaque (no estilo reportagem especial) em um e-mail que não contém outros assuntos. Já a categoria imagem diz respeito à maneira como tal assunto é salientado, pois se há imagens (fotos, artes gráficas ou algo do tipo) infere-se que o assunto é percebido como mais relevante; 4) personagens destacados (se a pesquisa é feita por professores, investigadores ou alunos da UFRN); 5) se é sobre investigação já finalizada ou em andamento.

Essas categorias foram configuradas após realizarmos uma leitura flutuante sobre o conteúdo, ainda na fase da pré-análise, observando as colocações de Aguiar (2012), sobre o teor do material divulgado pelas assessorias de comunicação em universidades; de Herbelê (2012), a respeito das maneiras de midiatização do discurso científico; e das pesquisas de Teixeira (2016), Campos (2018), Passos Filho (2018) e Costa e Lopes (2020) a respeito das experiências de divulgação científica por parte de universidades públicas brasileiras. Após esta etapa, houve a exploração do material e o tratamento dos resultados (BARDIN, 1977). Ressaltamos que as categorias não são autoexcludentes: um conteúdo analisado pode, por exemplo, ser relacionado à pesquisa científica e a evento, ou no aspecto formal pode ser curto e conter imagem.

Como defende Bardin (1977), ao optarmos por unir uma categorização do tipo semântica (temática) a uma análise formal (textual), formulamos inferências sobre o contexto da produção e consumo do material coletado e não nos detivemos apenas à mera quantificação de dados, pois entendemos que a análise de conteúdo deve proporcionar ao pesquisador a possibilidade de aprender com o que determinado conjunto de dados revela, desvendando o que de latente há no material.

\section{Análise e resultados}

A primeira análise que realizamos demonstra que, no período da pesquisa, o número de textos relacionados a pesquisas científicas foi relativamente baixo em relação às outras 
categorias: apenas 12 textos dos 144 analisados (como mostra o gráfico 1), sendo que destes, cinco também davam conta de eventos. Ou seja, a notícia tratava, por exemplo, de uma pesquisa divulgada em evento ou de evento no qual seriam divulgadas investigações científicas. É justamente a categoria "eventos" que recebeu mais atenção da assessoria de comunicação da UFRN neste período: são 64 textos relacionadas a este tópico. Enquadramos nesta categoria materiais que diziam respeito a seminários, conferências, palestras, exibições de filmes etc. Outra categoria robusta foi a "serviços". Com 53 textos, ela agrega informações relacionadas à realização de ações por parte da UFRN junto à comunidade acadêmica ou ao público no geral. A ampliação da maternidade escola ou a divulgação de um concurso para preenchimento de vagas em uma pós-graduação, por exemplo, integram esta classificação. Já a categoria "institucional" agrega os textos (15 no total) que abordam informações administrativas ou destacam personagens da administração, a exemplo da então reitora Ângela Maria Paiva Cruz ou de algum(a) pró-reitor(a). Assim, a participação da reitora em uma homenagem à UFRN, na Câmara dos Deputados, em Brasília, e a inauguração de um laboratório de economia fazem parte desta categoria.

Gráfico 1 - Categorização temática dos textos

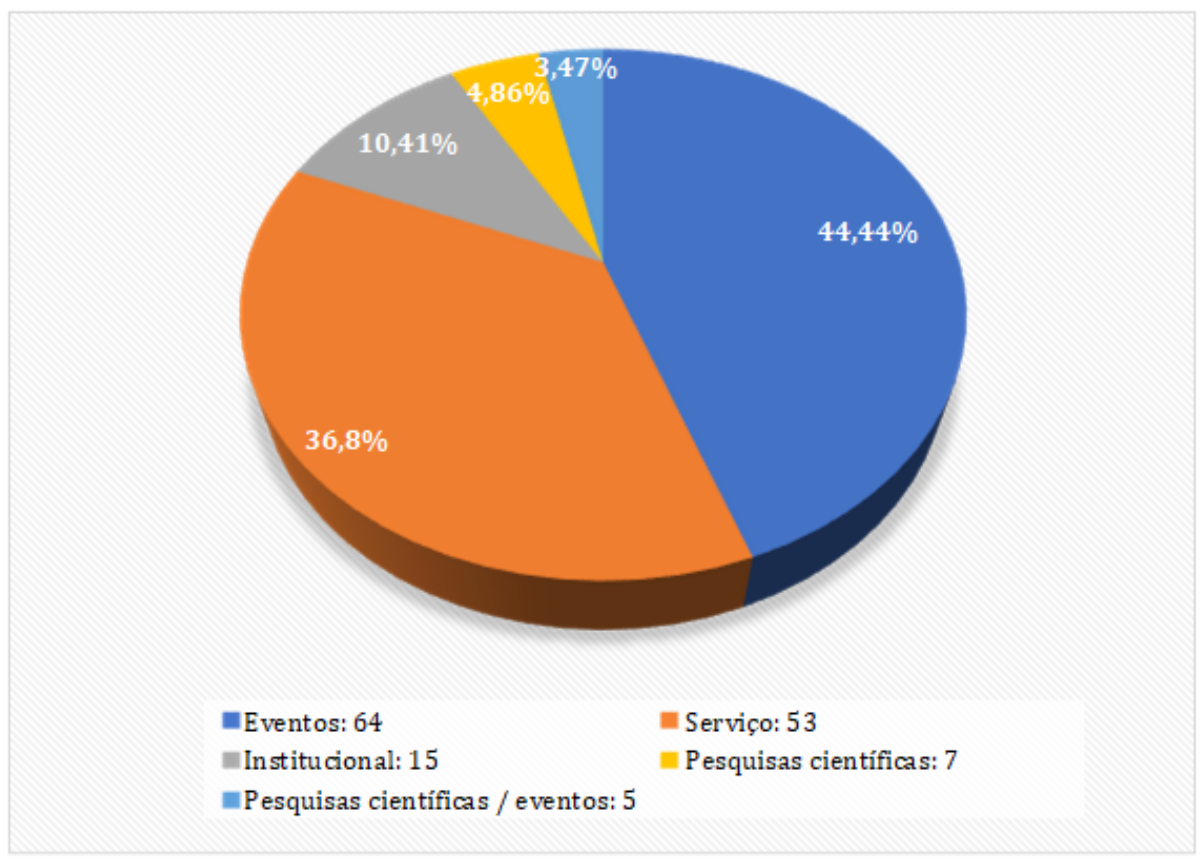

Fonte: Elaborado pelos autores.

Esses dados vão ao encontro do que Aguiar (2012) aponta ao explicar que as assessorias de comunicação das universidades ainda dão pouco espaço à divulgação 
científica e costumam salientar a comunicação institucional (ligada geralmente aos dirigentes das universidades): "Seus conteúdos são, por isso, fortemente marcados pela divulgação de eventos acadêmicos e de atos administrativos, a maior parte de interesse para o público interno." (AGUIAR, 2012, p. 30).

Com relação à observação sobre as informações sobre pesquisas científicas (gráfico 2), percebemos que há uma inclinação maior à divulgação de assuntos relacionados às ciências naturais (nove textos tratavam de disciplinas ligadas à essa área) em detrimento às ciências sociais (quatro). Vale salientar que um deles tratava tanto de ciências naturais como sociais ao divulgar pesquisas de doutorado e mestrado em ambas as áreas respectivamente. Podemos inferir que essa discrepância é reflexo da diferença no financiamento dessas áreas científicas no Brasil, já que as ciências naturais recebem dos órgãos fomentadores de pesquisas mais recursos do que as sociais (CAPES, 2018; CNPQ, 2020). Ressaltamos que na divisão das ciências de Fachin (2005) há as ciências formais, que englobam os estudos das ideias (matemática, lógica, computação): não encontradas na nossa investigação; e as ciências factuais, que agregam estudos dos fatos (naturais e humanas): identificadas nesta pesquisa.

Gráfico 2 - Pesquisa científica. Subcategoria: área científica

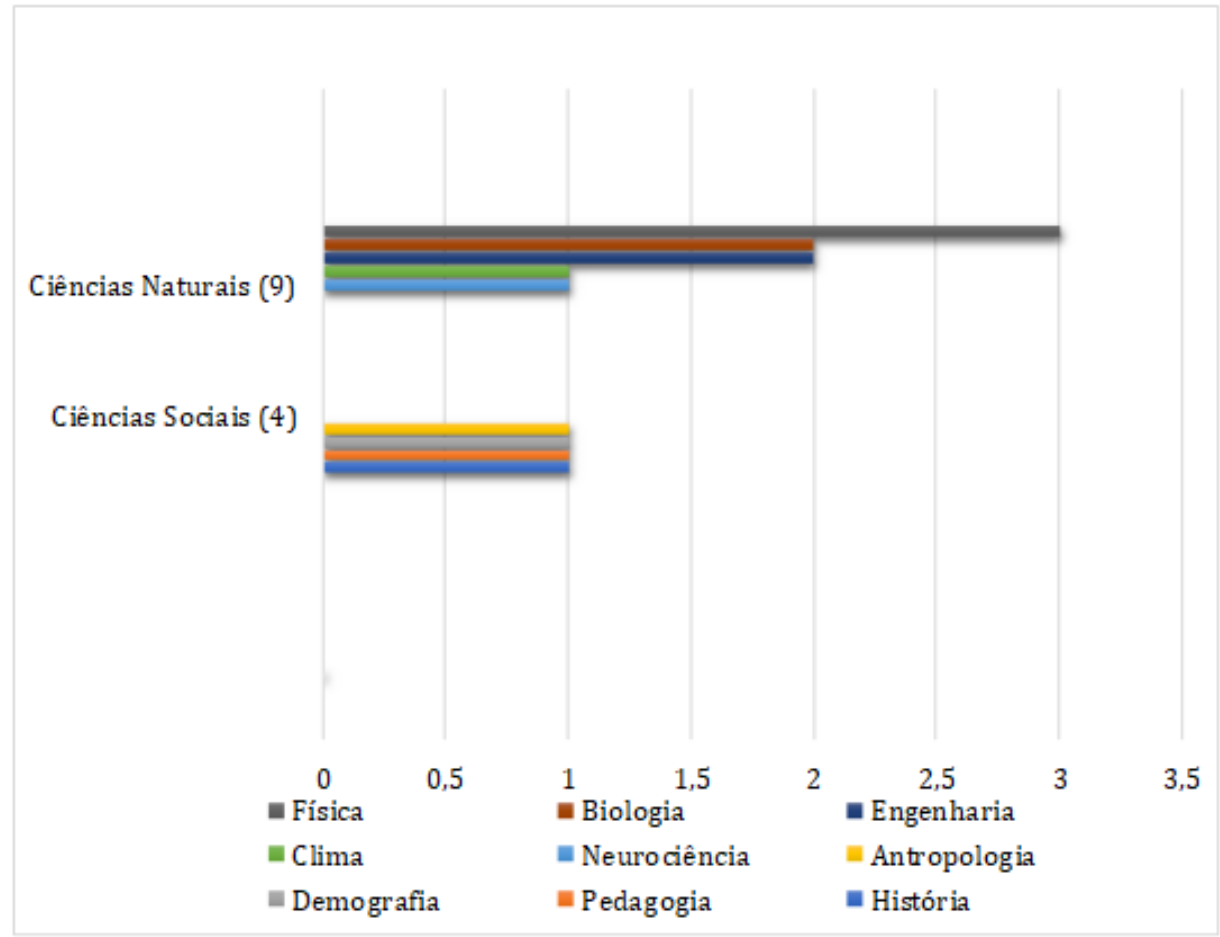

Fonte: Elaborado pelos autores. 
Também observamos as informações sobre pesquisas científicas no que diz respeito à abrangência geográfica (gráfico 3). Pesquisas de caráter nacional têm mais espaço (cinco no total), enquanto as relacionadas ao ambiente local (cidade de Natal) / estadual (Rio Grande do Norte) estiveram presentes em três textos. Já as pesquisas de abrangência internacional foram destacadas também em três textos. Salientamos que um deles tratava de uma pesquisa local e de outra nacional. Uma variedade que demonstra a pujança acadêmica da universidade, com cerca de 200 cursos de graduação e pós-graduação e aproximadamente 43 mil estudantes (UFRN, 2020a).

Um dos materiais de abrangência internacional tratava de um evento na área de física que seria totalmente realizado na língua inglesa. Percebe-se a adequação da universidade à imposição da língua inglesa como idioma científico internacional e a tentativa de consolidar o caráter transnacional do Instituto Internacional de Física da UFRN. Não por acaso a área de física foi a mais divulgada nos textos sobre pesquisas científicas (ver gráfico 2).

Gráfico 3 - Pesquisa científica. Subcategoria: abrangência geográfica

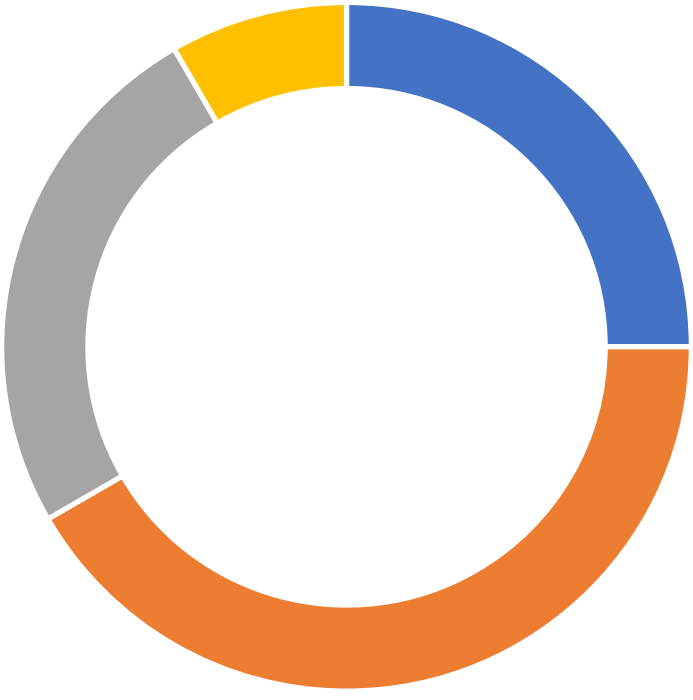

- Local/ Estadual: 3 "Nacional:5 "Internacional: 3 "Local/ Estadual/ Nacional: 1

Fonte: Elaborado pelos autores.

Outra subcategoria a que damos destaque é a extensão textual. Embora pareça formal e meramente quantitativa, esta avaliação é importante pois demonstra o espaço dado 
ao assunto no boletim. Como revela o gráfico 4, os textos de tamanho médio são os mais comuns (nove ao todo), os textos curtos somaram duas publicações e apenas um texto possui extensão "grande" (figuras 2 e 2.1); somente este conteve imagens. Este último citado foi publicado no chamado "Boletim Especial" que é enviado dando amplo destaque e aprofundamento a um assunto. Neste texto em específico, as ciências biológicas foram salientadas através de pesquisas sobre medicamentos fitoterápicos. Com fotos do pesquisador chefe, do laboratório e de plantas diversas, a publicação explicita minunciosamente a questão da abertura do Sistema Único de Saúde (SUS), no Brasil, para medicamentos deste tipo e explica como a UFRN contribui para a pesquisa nessa área.

Gráfico 4 - Pesquisa científica. Subcategoria: extensão textual

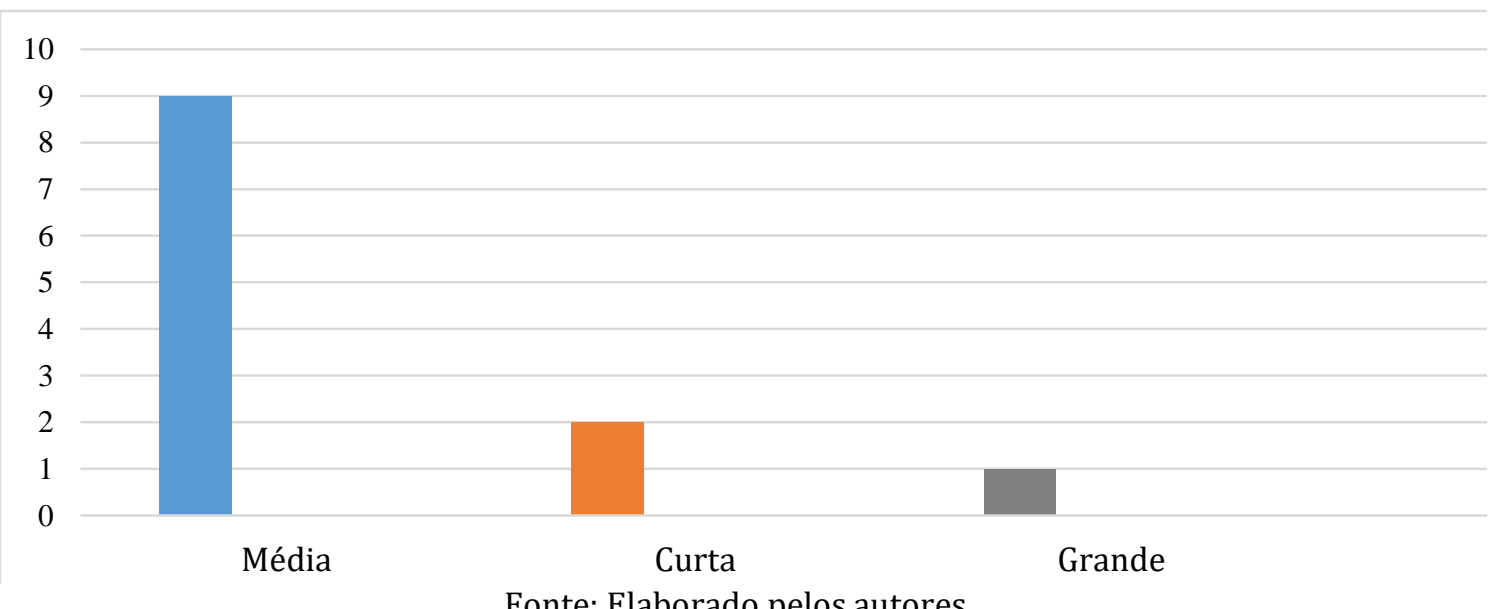

Enfatizamos ainda o destaque dado aos pesquisadores e alunos da UFRN nos textos analisados dentro da categoria "pesquisas científicas". Dez das doze unidades de análise relacionam-se a acadêmicos da UFRN, demonstrando que a assessoria de comunicação da universidade se preocupa em divulgar as demandas da comunidade acadêmica, cumprindo seu papel de salientar o trabalho dos investigadores da instituição, garantindo que as chamadas notícias institucionais sejam compostas com fatos e personagens da universidade, como orientam os manuais de assessoria de comunicação. Esta situação legitima tanto a instituição como os especialistas nela envolvidos como fontes credíveis junto ao público em geral e aos meios jornalísticos. Como explica Monteiro (2020, p. 120),

[...] nas instituições voltadas para as áreas de medicina, segurança pública, ou naquelas cuja atividade envolve conhecimento jurídico ou científico, por exemplo, aos requisitos exigidos de uma fonte institucional - 
afirmações "objetivas", autorizadas, "dignas de crédito" - está agregada sua condição de "perito" ou "autoridade" no assunto.

Figura 2 - Boletim especial (grande) recebido por e-mail

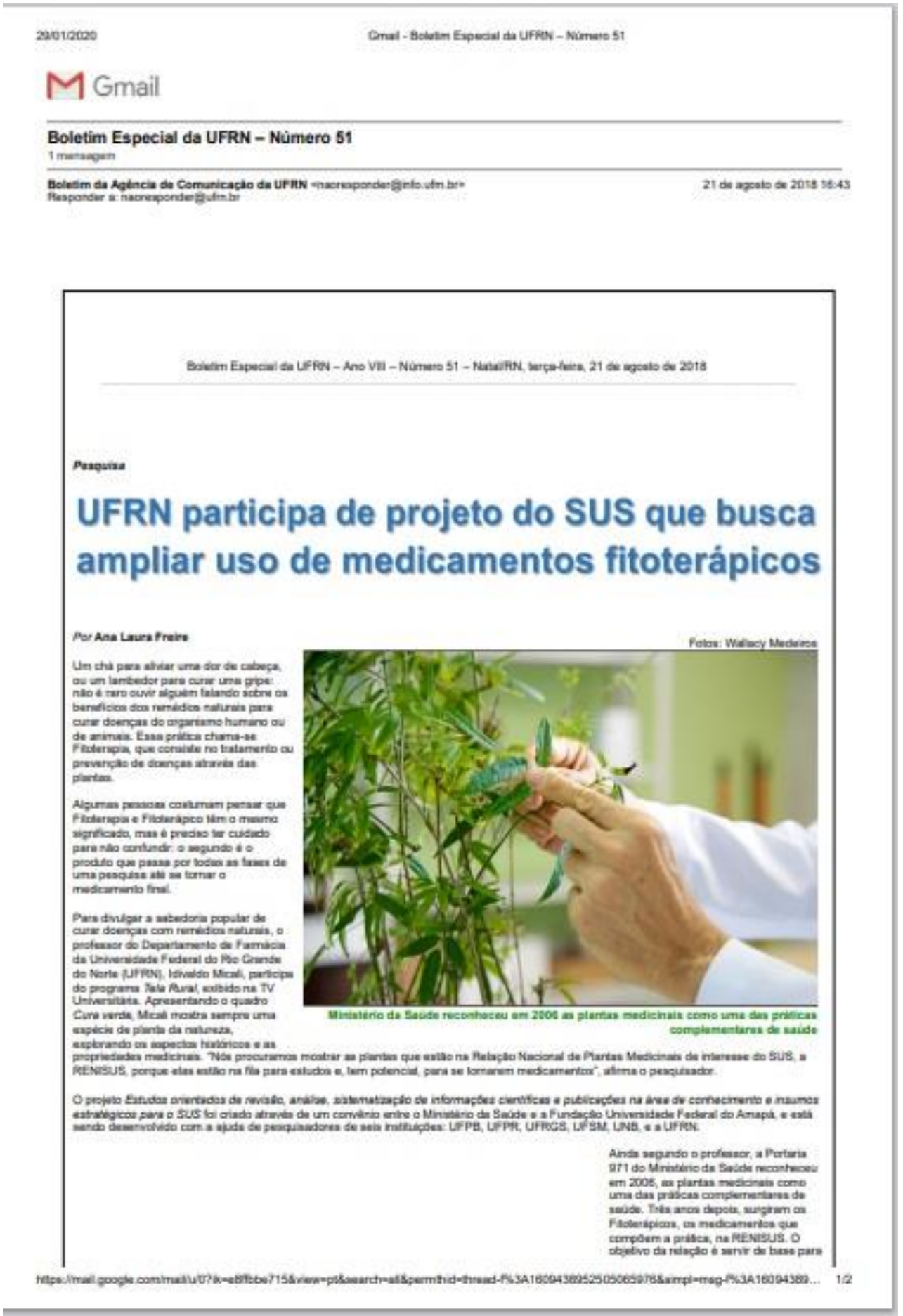

Fonte: Boletim Especial da UFRN (AGÊNCIA DE COMUNICAÇÃO DA UFRN, 2018). 
Figura 2.1 - Boletim especial (grande) recebido por e-mail

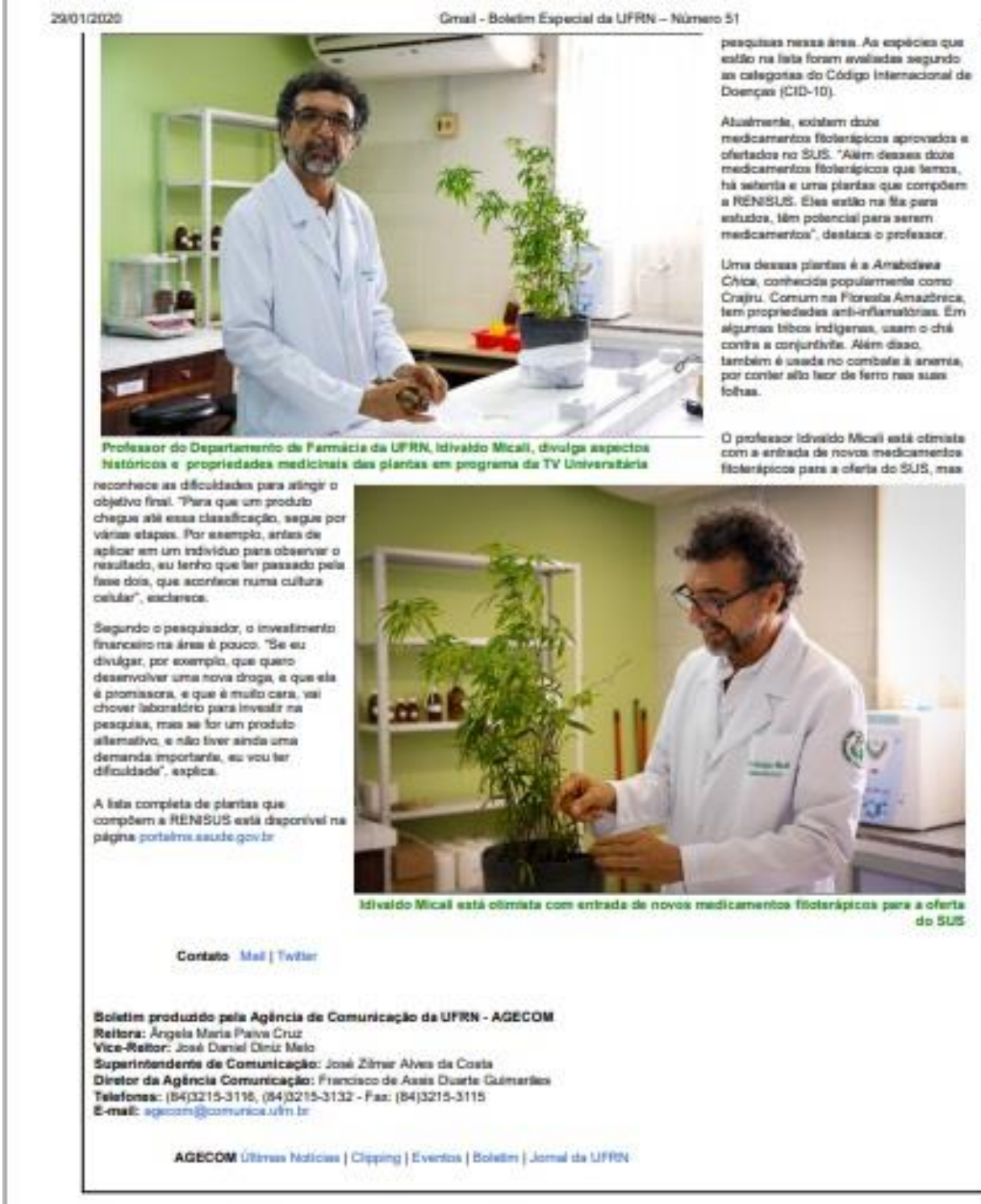

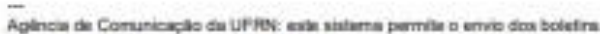

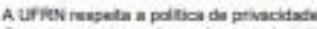

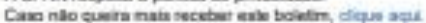

Fonte: Boletim Especial da UFRN (AGÊNCIA DE COMUNICAÇÃO DA UFRN, 2018).

Passando para outra subcategoria (se as notícias do boletim tratavam de pesquisas acabadas ou não), percebemos que cinco textos abordavam investigações acabadas. Os demais ou não explicitavam essa questão ou tratavam de trabalhos em andamento. Um 
número baixo se levarmos em consideração a quantidade elevada de programas de pósgraduação na UFRN (quase 100) (UFRN, 2020b), os quais formam pesquisadores em diversas áreas frequentemente. Infere-se, portanto, que a comunicação da assessoria da universidade junto aos centros, departamentos e programas de pós-graduação da instituição não se dá de maneira plena a ponto de garantir um acompanhamento do andamento das pesquisas. Isso se explica devido à alta demanda de produção de conteúdo junto à assessoria que, como ficou comprovado nesta pesquisa, tem que se desdobrar para divulgar assuntos científicos, administrativos e institucionais. Como demonstraram Costa e Lopes (2020) há uma relação direta entre a estrutura financeira e de pessoal da instituição de ensino e pesquisa e o vigor da divulgação científica da mesma. Esta situação é clara na UFRN, num contexto em que este tipo de assunto recebe menos atenção quando comparado a outros ligados à universidade.

\section{Considerações finais}

Não há dúvidas de que o boletim informativo @UFRNotícias cumpre seu papel ao divulgar o cotidiano da Universidade Federal do Rio Grande do Norte. Dentro das possibilidades de disseminação de conteúdos oferecidas pelas TICs, essa ferramenta abrange uma vasta gama de assuntos e é direcionada a diversos públicos (o interno da UFRN: alunos, professores e servidores técnico-administrativos; e o externo: jornalistas que recebem os e-mails e público em geral que acessa esse material no site da universidade).

As hipóteses levantadas neste artigo foram validadas: com formato padronizado, o boletim tem caráter heterogêneo dando conta de maneira abrangente das demandas gerais da comunidade acadêmica, atendendo também à lógica do imediatismo e da exigência por novidade do jornalismo na atualidade. No que diz respeito a dar divulgação a pesquisas científicas, a publicação ficou aquém de suas possibilidades. Menos de $10 \%$ do total de textos analisados tratarem de pesquisas é um percentual muito baixo para uma universidade com reconhecimento internacional como é a UFRN. Ou seja, a divulgação de pesquisas científicas não tem destaque quando comparada à publicização de eventos, serviços e assuntos institucionais, o que compromete o caráter de comunicação pública do citado material informativo.

Além disso, vale salientar que os textos relacionados a pesquisas científicas, na sua maioria, são superficiais, indiciais e apenas apresentam os temas das investigações (com 
uma exceção apenas), limitando-se a uma linguagem simples, sem explicar como aqueles trabalhos podem influenciar diretamente a vida das pessoas, numa tentativa de se aproximar de uma linguagem jornalística, mais palatável, reduzindo complexidades (LUHMANN, 2005). Aguiar (2012) explica que é comum o envio por parte das assessorias de materiais semiprontos para as redações, já que a possibilidade de os releases serem aproveitados na íntegra é bastante alta, devido aos constrangimentos organizacionais percebidos na rotina jornalística.

Dentro deste contexto, há nos textos algumas características que também são encontradas em notícias sobre pesquisas científicas na mídia jornalística no geral: "fragmentação, redução de sentido, conceitos jogados sem discussão [...], informação linear não analítica." (HERBELÊ, 2012, p. 139).

No entanto, há limitações nesta investigação. Entendemos que este quadro pode ser validado ou refutado com outros métodos, amostras e lapsos temporais. Pesquisas em outros períodos ou considerando um período maior poderiam dar outra visão sobre o assunto. Outra sugestão para ampliar este estudo é realizar entrevistas com funcionários da Agência de Comunicação da UFRN (jornalistas ou não) para entender os procedimentos de escrita e os critérios de noticiabilidade que regem esta publicação. Realizar observação nãoparticipante, para perceber as rotinas e os constrangimentos organizacionais com os quais os profissionais têm que lidar, também seria pertinente para perceber em que medida isso influencia nas decisões a serem tomadas quanto ao que deve ser publicado ou não.

Consideradas a realização deste estudo em específico e as limitações expostas, fica a necessidade de se aprofundar essa temática de pesquisa, pois é necessário que os investigadores olhem para os sistemas de divulgação da ciência, numa perspectiva de comunicação pública cidadã, para tentar perceber quais são as falhas na comunicação (mediada por meios jornalísticos ou não) com o público em geral e propor alternativas para que mais pessoas tenham contato com ciência e possam compreender a importância disso nas suas vidas. 


\section{Referências}

AGÊNCIA DE COMUNICAÇÃO DA UFRN. [Boletim diário da UFRN]. Destinatário: Raul Ramalho. Natal, 23 ago. 2018. 1 mensagem eletrônica.

AGUIAR, Sônia. 0 papel das universidades na midiatização das ciências: cenários, processos e estratégias. In: FAUSTO NETO, Antônio (org.). Midiatização da ciência: cenários, desafios, possibilidades. Campina Grande: EDUEPB, 2012. p. 15-40.

ALMEIDA, Sandra Regina G. Cortes de verbas na ciência ameaçam o futuro do país. Folha de S.Paulo, São Paulo, 7 jul. 2021.

BARDIN, Laurence. Análise de conteúdo. Lisboa: Edições 70, 1977.

BRANDÃO, Elizabeth Pazito. Usos e Significados do Conceito Comunicação Pública. In: VI Encontro dos Núcleos de Pesquisa da Intercom, 2006, Brasília. Anais [...]. Brasília: Intercom - Sociedade Brasileira de Estudos Interdisciplinares da Comunicação, 2006. p. 1-14.

BUENO, Wilson da Costa. Comunicação empresarial: políticas e estratégias. São Paulo: Saraiva, 2009.

BUENO, Wilson da Costa. Estratégias de comunicação nas mídias sociais. In: BUENO, Wilson da Costa (org.). Estratégias de comunicação para as mídias sociais. Barueri, SP: Manole, 2015. p. 123-144.

CAMPOS, Luana Rodrigues. Comunicação pública da ciência e as pesquisas sobre o pantanal: reflexões preliminares sobre as assessorias de comunicação em universidades públicas.

Revista do EDICC (Encontro de Divulgação de Ciência e Cultura), Campinas, v. 4, p. 1-9, 2018.

CHIZZOTTI, Antônio. Pesquisa qualitativa em ciências humanas e sociais. Petrópolis: Vozes, 2006.

CONSELHO NACIONAL DE PESQUISA (CNPq). Séries históricas. 2018. Disponível em: http://www.cnpq.br/series-historicas. Acesso em: 02 ago. 2020.

COORDENAÇÃO DE APERFEIÇOAMENTO DO PESSOAL DE NÍVEL SUPERIOR (CAPES). Geocapes - Sistema de informações georreferenciadas. 2017. Disponível em: https://geocapes.capes.gov.br/geocapes/. Acesso em: 02 ago. 2020.

COSTA, Marcílio José de Sousa; LOPES, Sônia Aguiar. A comunicação pública da ciência nos portais das universidades da região nordeste. Revista do EDICC (Encontro de Divulgação de Ciência e Cultura), Campinas, v. 6, p. 103-113, 2020.

COUTINHO, Clara Pereira. Metodologia de investigação em ciências sociais e humanas: teoria e prática. 2. ed. Coimbra: Almedina, 2015. 421 p. 
CURVELLO, João José Azevedo. Legitimação das assessorias de comunicação nas organizações. In: DUARTE, Jorge (org.). Assessoria de imprensa e relacionamento com a mídia. 4. ed. São Paulo: Atlas, 2020. p. 96-114.

DUARTE, Jorge. Comunicação pública. In: LOPES, Boanerges (org.). Gestão em comunicação empresarial: teoria e técnica. Juiz de Fora, MG: Multimeios, 2007. p. 63-71.

DUARTE, Jorge. Produtos e serviços de uma assessoria de imprensa. In: DUARTE, Jorge (org.). Assessoria de imprensa e relacionamento com a mídia: teoria e técnica. 4. ed. São Paulo: Atlas, 2016. p. 254-273.

FACHIN, Odília. Fundamentos de metodologia. 5. ed. São Paulo: Saraiva, 2005.

FREIRE, Ana Laura; AGÊNCIA DE COMUNICAÇÃO DA UFRN. [Boletim especial da UFRN]. Destinatário: Raul Ramalho. Natal, 21 ago. 2018. 1 Mensagem eletrônica.

KOPPLIN, Elisa; FERRARETO, Luiz Artur. Assessoria de imprensa: teoria e prática. 5. ed. São Paulo: Summus, 2009.

HEPP, Andreas; HASEBRINK, Uwe. Researching transforming communications in times of deep mediatization: a figurational approach. In: HEPP, Andreas; BREITER, Andreas; HASEBRINK, Uwe (orgs.). Transforming communications: studies in cross-media research. Cham, Switzerland: Palgrave Macmillan, 2018. p. 15-48.

HERBELÊ, Antônio. Interações possíveis na midiatização da ciência. In: FAUSTO NETO, Antônio (org.). Midiatização da ciência: cenários, desafios, possibilidades. Campina Grande: EDUEPB, 2012. p. 127-142.

HERSCOVITZ, Heloiza Golbspan. Análise de conteúdo em jornalismo. In: LAGO, Cláudia; BENETTI, Marcia (orgs.). Metodologia de pesquisa em jornalismo. 3. ed. Petrópolis: Vozes, 2010. p. $123-142$.

IVANISSEVICH, Alicia. Por que divulgar ciência no Brasil. In: FAUSTO NETO, Antônio (org.). Midiatização da ciência: cenários, desafios, possibilidades. Campina Grande: EDUEPB, 2012. p. 97-106.

LUHMANN, Niklas. A realidade dos meios de comunicação. São Paulo: Paulus, 2005.

MONTEIRO, Graça França. A notícia institucional. In: DUARTE, Jorge (org.). Assessoria de imprensa e relacionamento com a mídia. 4. ed. São Paulo: Atlas, 2016. p. 115-136.

MOURA, Mariluce. Universidades públicas respondem por mais de 95\% da produção científica do Brasil. Ciência na rua, São Paulo, 11 abr. 2019. Disponível em:

https://ciencianarua.net/universidades-publicas-respondem-por-mais-de-95-da-producaocientifica-do-brasil/ . Acesso em: 04 dez. 2021.

OLIVEIRA, Maria Marly de. Como fazer pesquisa qualitativa. Petrópolis: Vozes, 2007. 
OURIQUES, Nildo. Ciência e pós-graduação na universidade brasileira. In: RAMPINELLI, Waldir José; OURIQUES, Nildo (orgs.). Crítica à razão acadêmica: reflexão sobre a universidade contemporânea. Florianópolis: Insular, 2011. p. 73-107.

PASSOS JÚNIOR, José Francisco dos. Caminhos e desafios para uma política de comunicação institucional integrada na Universidade Federal Rural do Semi-Árido UFERSA. 2018. 140 f. Dissertação (Mestrado em Gestão de Processos Institucionais) Centro de Ciências Humanas, Letras e Artes (CCHLA), Universidade Federal do Rio Grande do Norte, Natal, 2018.

REGO, Teresa Cristina. Produtivismo, pesquisa e comunicação científica: entre o veneno e o remédio. Educação e pesquisa, São Paulo, v. 40, n. 2, 2014, p. 325-346.

TEIXEIRA, Danielle Tavares. Comunicação institucional e universidade: diretrizes para a divulgação científica no estado do Mato Grosso. 2016. 263 f. Tese (Doutorado em Comunicação Social) - Escola de Comunicação, Educação e Humanidades, Universidade Metodista de São Paulo, São Bernardo do Campo, 2016.

UNIVERSIDADE FEDERAL DO RIO GRANDE DO NORTE. Programas de Pós-graduação Stricto Sensu. 2020. Disponível em: https://www.ufrn.br/academico/ensino/posgraduacao/stricto-sensu/cursos. Acesso em: 27 ago. 2020.

UNIVERSIDADE FEDERAL DO RIO GRANDE DO NORTE. Sobre a UFRN. 2020. Disponível em: https://www.ufrn.br/institucional/sobre-a-ufrn. Acesso em: 27 ago. 2020.

YIN, Robert K. Estudo de caso: planejamento e métodos. 2. ed. Porto Alegre: Bookman, 2001.

\title{
Dissemination of science in public universities: content analysis of information produced by a press office
}

\begin{abstract}
This article aims to contribute to the discussions on the work of the press office / communication in the dissemination of scientific research carried out in public universities. To this end, it analyzes the contents of the newsletter @UFRNotícias, produced by the Communication Agency of the Federal University of Rio Grande do Norte, in Brazil, related to scientific investigations carried out in the aforementioned organization and to administrative themes (events, services and institutional dissemination). The theoretical debate involves concepts of communication and press consultancy, public communication associated with scientific dissemination and the importance of organizational and strategic communication in the consolidation of the image and the social legitimation of a public teaching and
\end{abstract}


research institution. As methodology, content analysis was used to formulate thematic categories related to scientific dissemination, observe the format of the media product and make inferences about the conditions of production of the material and about the social and institutional context in which it is inserted. The sample consists of 24 newsletters (144 texts) sent in August 2018. Results show that the contents related to scientific research have little prominence (absence of photos and videos) and space in the newsletter (about $8 \%$ of the total), and they are mostly superficial. The standardized format and heterogeneous coverage demonstrate an attempt to disseminate content that serves the interests of different audiences such as journalists and the academic community.

\section{Keywords}

Scientific divulgation; Communication and press advisory; Public communication; Public university; @UFRNews

\section{Autoria para correspondência}

Raul Ramalho

raulramalhojornalistacg@gmail.com

\section{Como citar}

RAMALHO, Raul; GRADIM, Anabela. Divulgação da ciência na universidade pública: análise de conteúdo de informativo produzido por uma assessoria de comunicação. Intexto, Porto Alegre, n. 53, e-107073, jan./dez. 2022. DOI: http://dx.doi.org/10.19132/1807-8583202253.107073

Recebido em 31/08/2020

Aceito em 04/11/2021 